American Journal of Applied Sciences 2 (11): 1493-1498, 2005

ISSN 1546-9239

(c) 2005 Science Publications

\title{
Effect of Geometry and Dimensionless Parameters on Heat Transfer Characteristics of a Closed-end Oscillating Heat-pipe at Vertical Position
}

\author{
S. Rittidech and K. Phalasin \\ Faculty of Engineering, Mahasarakham University, Thailand
}

\begin{abstract}
This heat transfer characteristics of a closed-end oscillating heat-pipe (CEOHP) depend on a number of parameters. They are the number of turns, inner diameter of the tube, aspect ratio and the dimensionless parameters of heat transfer. The CEOHPs used to employ a copper tube with inner diameter of $0.66,1.09$ and $2.03 \mathrm{~mm}$. The lengths of the evaporator, adiabatic and condenser sections were equal and changed to 50,100 and $150 \mathrm{~mm}$. R141b was used as the working fluids with filling ratio of $50 \%$ by total volume. The meandering turns of 10,20 and 40.The evaporator section was heated by hot water and the condenser section was cooled by distilled water. The experimental inclination angles were $0,20,40,60,80$ and 90 degree from the horizontal plane. The controlled temperature at the adiabatic section of $50^{\circ} \mathrm{C}$. When the system reached the steady state, the temperature and the flow rate of the cooling substance was recorded in order to calculate the heat transfer rate of the CEOHPs. The experimental results showed that the heat flux decreases with an increasing number of turns and decreases with an increasing aspect ratio. The heat flux increases with an increasing inner diameter. A correlation to predict the heat transfer rate at vertical position can be established.
\end{abstract}

Key words: Closed-end oscillating heat-pipe, heat transfer characteristics, geometry, dimensionless parameter

\section{INTRODUCTION}

When a heat transfer device for high heat lode is made, conventional heat pipes several limitations, such as the capillary limit when the diameter of the pipe is narrow and the entertainment limit. This problem becomes especially crucial when using heat pipes to cool electronic devices. Because of these limitations, three different types of long capillary tubes are commonly employed as shown in Fig. 1. The first is a closed-loop oscillating heat pipe (CLOHP), which is connected at both ends of the tube to form a closed loop. The second is a CLOHP with a check value, which makes the working move in a specified direction .The last is a closed end oscillating heat pipe (CEOHP), which is closed at both ends. Of these OHPs the CEOHP consist of a single long section of meandering capillary tubing. The heat transfer of CEOHP occurs because of self-exciting oscillation of the working fluid. As the criterion to find the maximum inner diameter of a CEOHP,${ }^{[1]}$ assumed that where the vapor bubble is formed alternately with the liquid plug within the tube, depended on the properties of the working fluid as:

$d_{\max } \leq 2 \sqrt{\frac{\sigma}{\rho g}}$

The advantages of CEOHPs are its properties of transferring heat in any orientation, its quick response

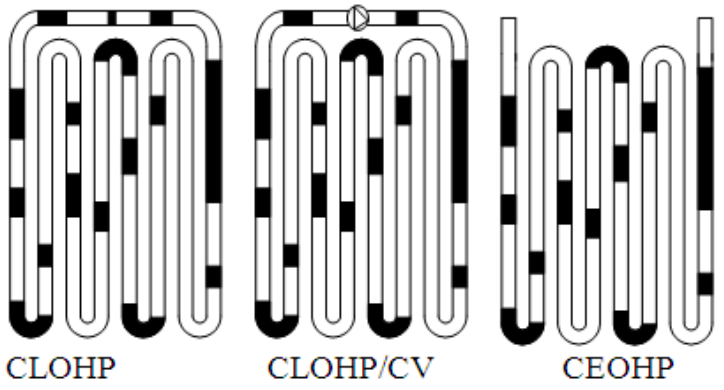

Fig. 1: Types of oscillating heat pipe

and its internal wickless structure. The heat transfer characteristics of the CEOHP are usually shown by its capability of transferring heat by area or heat flux (q) at 90 (vertical plane, when the condenser sections are over evaporator section). Rittidech et al. ${ }^{[2]}$ studied a correlation to predict heat transfer characteristics of a closed-end oscillating heat pipe at normal operating condition (horizontal position). As the criterion to find the In order to totally understand the heat transfer characteristics of a CEOHP, systematic experimental works must be conducted. However, there has been little previous experimental research done on heat flux in vertical position. In order to obtain the heat transfer characteristics and to find correlation in vertical position of the CEOHP, more experiment research is

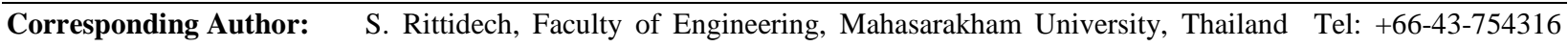
Fax: +66-43-754326 
required. It is, therefore, the objective of this research to experimentally investigate the following aspects of a CEOHP:

* To study the effects of the number of turns, inner diameter of the tube, aspect ratios and the dimensionless parameters on the heat transfer characteristics of a CEOHP in vertical position.

* Establish a correlation to predict the heat transfer characteristics of a CEOHP at vertical position.

Experimental setup and procedure: Figure 2 shows an experimental setup, which consists of a CEOHP with a heating bath for the evaporator section and a cooling bath for the condenser section. The CEOHPs were made of copper tubes. The temperature of evaporator and condenser section was controlled at 80 and $20^{\circ} \mathrm{C}$ respectively. The data logger (Yokogawa DX 200 with $\pm 0.1^{\circ} \mathrm{C}$ accuracy, 20 channel input and -200 to $1100^{\circ} \mathrm{C}$ measurement temperature range) was used with type $\mathrm{K}$ thermocouples (Omega with $\pm 1^{\circ} \mathrm{C}$ accuracy) attached to the inlet and outlet of the cooling jacket, to monitor the different temperatures. In order to calculate the heat transfer characteristics using the calorific method, eight sets of thermocouple were attached to the outside surface wall of the CEOHPs and data were recorded. These were 3 points on the evaporator, 3 points in the condenser and 2 points in the adiabatic section. A hot bath (TECHNE TE-10D with an operating range of -40 to $120^{\circ} \mathrm{C}$ and $\pm 0.01^{\circ} \mathrm{C}$ accuracy) was used to pump hot water into the heating jacket at the temperatures of $80^{\circ} \mathrm{C}$. While the cold bath (EYELA CA-1111, volume $6.0 \mathrm{~L}$ with an operating temperature range of -20 to $30^{\circ} \mathrm{C}$ and $\pm 2^{\circ} \mathrm{C}$ accuracy) was used to pump the cooling water into the cooling jacket. The inlet temperature of the cooling water was maintained at $20^{\circ} \mathrm{C}$ and the floating Rota meter (Platon PTF2 ASS-C with a measure flow rate of $0.2 \mathrm{~L} / \mathrm{min}$ to $1.5 \mathrm{~L} / \mathrm{min}$ ) was used to measure the flow rate of the cooling medium. During the experiment the mass flow rate set at $1.3 \mathrm{~L} / \mathrm{min}$ with angle was set at $0-90^{\circ}$. When steady state was achieved, the temperature and flow rate of the cooling water was recorded. Using the calorific method, as the following equations; used them to calculate the heat transfer rate of the test CEOHPs:

$\mathrm{Q}=\mathrm{m}^{\circ} \mathrm{c}_{\mathrm{p}}\left(\mathrm{T}_{\text {out }}-\mathrm{T}_{\text {in }}\right)$

In order to thoroughly study the effect of all parameters to $\mathrm{Q}$ controlled parameters are:

Controlled parameters were:

* Working temperature of $50^{\circ} \mathrm{C}$.

* Working fluid R141b.

* Filling ratio of 50\% (by total volume).

* Inclination angle of 90 degrees.

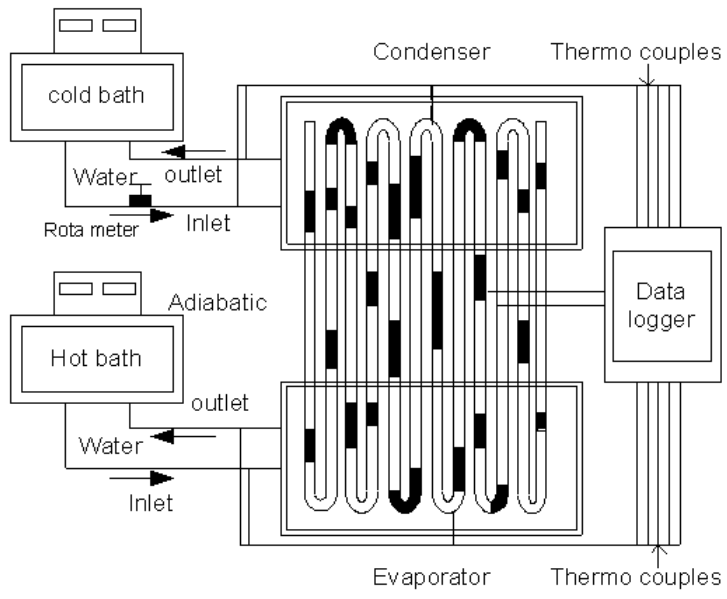

Fig. 2: Experimental setup

The variable parameters were:

* Number of turns 10,20 and 40 (to observe the effect of number of turns).

* Tube inner diameters of 0.66, 1.09 and $2.03 \mathrm{~mm}$. (to observe the effect of bond number).

* Aspect ratios $\left(\mathrm{L}_{\mathrm{e}} / \mathrm{d}\right)$ of 25 to 227 (to observe the effect of aspect ratios).

\section{RESULTS AND DISCUSSION}

It was necessary to change the heat transfer $(\mathrm{Q})$ of a CEOHP in vertical position, i.e., heat flux $\left(\mathrm{q}_{90}\right)$ and using the following equation (3):

$\mathrm{q}_{90}=\frac{\mathrm{Q}_{90}}{\mathrm{~A}_{\mathrm{O}}}$

The effects of geometry and dimensionless parameters on the heat transfer characteristics of a CEOHP at vertical position will be discussed together with the correlation.

\section{Effect of geometry:}

Effect of number of turns: In this experiment, the effect of the number of turns (n) on the heat flux of a CEOHP in vertical positions was considered. The experimental results clearly present the effect of the number of turns on heat flux in Fig. 3. This figure shows the relationship of the number of turns on the heat flux of a CEOHP with an inner diameter of 0.66 , 1.09 and $2.03 \mathrm{~mm}$. The lengths of evaporator of 50, 100 and $150 \mathrm{~mm}$. (The lengths of the evaporator, adiabatic and condenser sections were equal). R141b was used as the working fluid. It was seen that the number of turns increased, the heat flux increased, in the range between 10,20 and 40 turns. The heat flux increased from $21,648 \mathrm{~W} / \mathrm{m}^{2}, 30,098 \mathrm{~W} / \mathrm{m}^{2}$ and $65,080 \mathrm{~W} / \mathrm{m}^{2}$, when the number of turns 10, 20 and 40 respectively. 


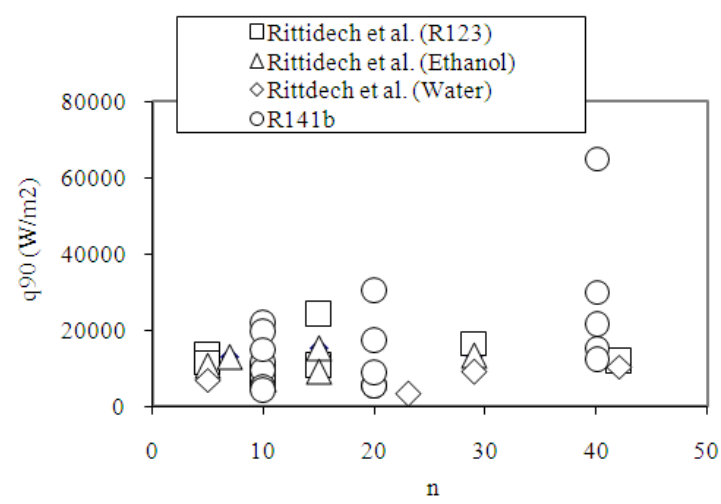

Fig. 3: Relationship of the number of turns and heat flux of CEOHP Di 0.66,1.09 and $2.03 \mathrm{~mm}, \mathrm{R} 141 \mathrm{~b}$

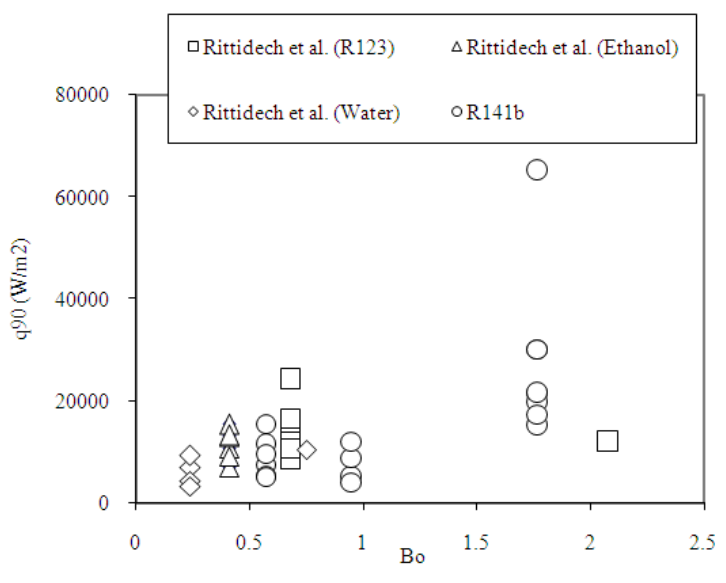

Fig. 4: Relationship of the Bond number and heat flux of CEOHP Di 0.66,1.09 and $2.03 \mathrm{~mm}, \mathrm{R} 141 \mathrm{~b}$

This experiment cannot be compared with ${ }^{[3]}$ because they were conducted with 5 to 42 turns. For this study, if the number of turns is high, the value of heat flux increases. It can be concluded that, if the number of turns increases the heat flux increases

Effect of inner diameter: Bond numbers represents the ratio of buoyancy force and surface tension force. In this experiment, the effect of the Bond numbers (Bo) on the heat flux of a CEOHP in the inclination angle of $90^{\circ}$ from horizontal plane was considered. The experimental results clearly present the effect of the Bond numbers to heat flux in Fig. 4, this figure shows the relationship of Bo on the heat flux of a CEOHP with Bo numbers of $0.57,0.95$ to 1.77 and number of turns 10, 20 and 40 respectively. R141b was used as the working fluid with filling ratio of $50 \%$ of the internal volume of the tube. The lengths of the evaporator, adiabatic and condenser sections were equal and varying the $\mathrm{L}_{\mathrm{e}} / \mathrm{d}$. It can be seen that when the Bond numbers increases from $0.57,0.95$ to 1.77 the maximum heat fluxes slightly increased.

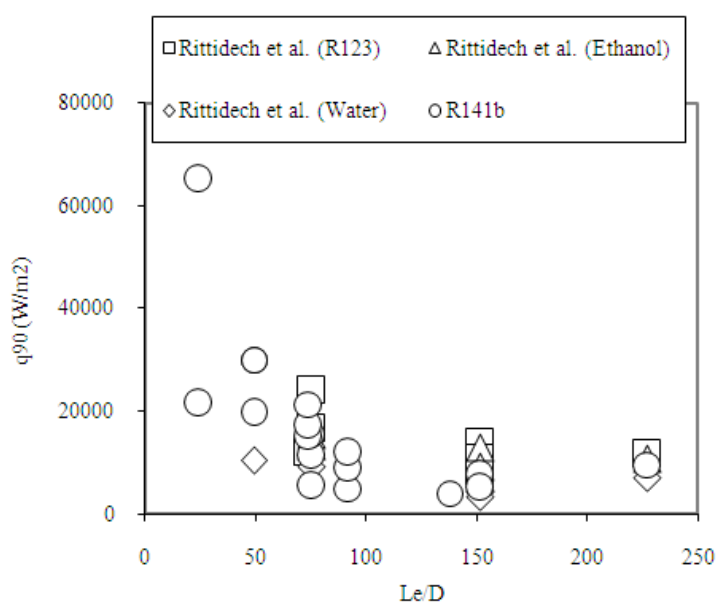

Fig. 5: Relationship of the Aspect ratios and heat flux of CEOHP Di 0.66,1.09 and $2.03 \mathrm{~mm}$. R141b, $\mathrm{L}_{\mathrm{e}} / \mathrm{D}$ $=25$ to 227

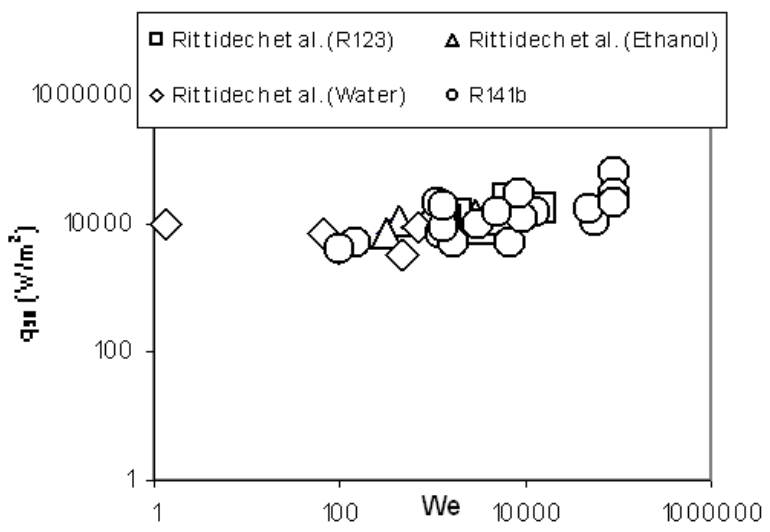

Fig. 6: Relationship of the Weber number and heat flux of CEOHP

In Bo 0.57, 0.95 and 1.77 the maximum heat fluxes were $24,145 \mathrm{~W} / \mathrm{m}^{2} \quad 12,079 \mathrm{~W} / \mathrm{m}^{2}$ and $65,080 \mathrm{~W} / \mathrm{m}^{2}$ respectively. For this study, if there is a Bo are increasing, the valve of heat flux increases. This is because, Bo is the ratio of buoyancy force to surface tension force working fluid, if the Bond number higher than one, it could be boiling phenomenon and could be higher heat transfer, in the other hand at the Bo lower than one it could be lower boiling phenomenon and low heat flux occurs. However if Bo is one, it shows that the ratio of buoyancy force to surface tension force working fluid, it will be equal. Could not boiling phenomenon and cannot heat flux occur. It can be concluded that, it was found from that the experiment, when the Bo increases the heat transfer rate slightly increases.

Effect of aspect ratios: In this experiment, the evaporator, adiabatic and condenser were of equal length. This paper will concentrate on study the effect 
of aspect ratios (Le/d) on heat flux of a CEOHP. The experimental results clearly present the effect of aspect ratios on heat flux. Figure 5 this figure shows the relationship of the aspect ratios to the heat flux of CEOHPs with an inner diameter of 0.66, 1.09 and 2.03 $\mathrm{mm}$ and number of turns 10,20 and 40 . R141b was used as the working fluid with filling ratio of $50 \%$ of the internal volume of the tube. The lengths of the evaporator, adiabatic and condenser sections were equal and varying the Le/d from 25 to 227. It was seen that, the maximum heat flux of each inner diameter was obtained at minimum Le/d by 25,46 and 76 . The maximum heat fluxes were $65,080 \mathrm{~W} / \mathrm{m}^{2}, 21,840 \mathrm{~W} / \mathrm{m}^{2}$ and $15,455 \mathrm{~W} / \mathrm{m}^{2}$ for an inner diameter of $2.03,1.09$ and $0.66 \mathrm{~mm}$ respectively. This experiment results can be compared with the data of [2], which used R123, ethanol and water, it can be seen that the Le/d increases from 25 to 227, the heat flux slightly decreases. This may be because, when the very small Le/d the boiling phenomenon approaches pool boiling and at pool boiling high heat flux occurs. On the other hand, at a high Le/d, the boiling phenomenon approaches boiling inside a confined channel at which low heat flux occurs.

Effect of dimensionless parameters: The dimensionless parameters, It will have the effect on the heat flux of a CEOHP at vertical position include the Weber numbers (We), Prandtl numbers (Pr), Jacob numbers (Ja), Kutaeladze numbers $(\mathrm{Ku})$ and the oscillations of the working fluid was $\left(\omega \mu v^{3} / \sigma^{2} \rho_{v}\right)$.We is the ratio of dynamic force to surface tension force and the working liquid. It represents the counter flow phenomena between the free surfaces of liquid film and vapor bubbles in the tube. This may occur when the vapor bubble moves to the condenser section then the liquid film, which is formed around the internal wall, flow in the opposite direction to the vapor bubble. Pr is the ratio of momentum diffusivity to thermal diffusivity of vapor bubbles. They represent the convection heat transfer phenomena in the tube and this may occur when the vapor bubble moves from the evaporator to condenser sections and the medium of convection heat transfer Therefore, the size and amount of vapor bubble which flow to the condenser section change slightly. Ja is the ratio of sensible heat to latent heat of the working fluid. $\mathrm{Ku}$ is the ratio of heat flux of a CEOHP to the critical heat flux of the working fluid. It represents the pool boiling phenomena of working fluid in the evaporator sections of a CEOHP. And $\left(\omega \mu v^{3} / \sigma^{2} \rho_{v}\right)$ represents the self-excited oscillation happened by the pressure movement of pressure wave because if occur pool boiling phenomena at an evaporator section of a CEOHP as shown in Fig. 10. From the consideration of each parameter, it was found that the $\mathrm{Ja}, \mathrm{Pr}$ and $\left(\omega \mu v^{3} / \sigma^{2} \rho_{v}\right)$ were scattered as shown in Fig. 7, 8 and 10. However, the important parameters had a relationship to the heat flux of a CEOHP. Such as, We and $\mathrm{Ku}$ had a linear relationship to the heat flux because there was a fixed pattern for all the data as shown in Fig. 6 and 9. Furthermore, n, Bo and Le/d had a relationship to the heat flux because there was a fixed pattern for all the data as shown in Fig. 3, 4 and 5. Thus n, Bo, Le/d, We, Pr, Ja, Ku and $\left(\omega \mu v^{3} / \sigma^{2} \rho_{v}\right)$ can be used to formulate a correlation for heat flux of a CEOHP at vertical position.

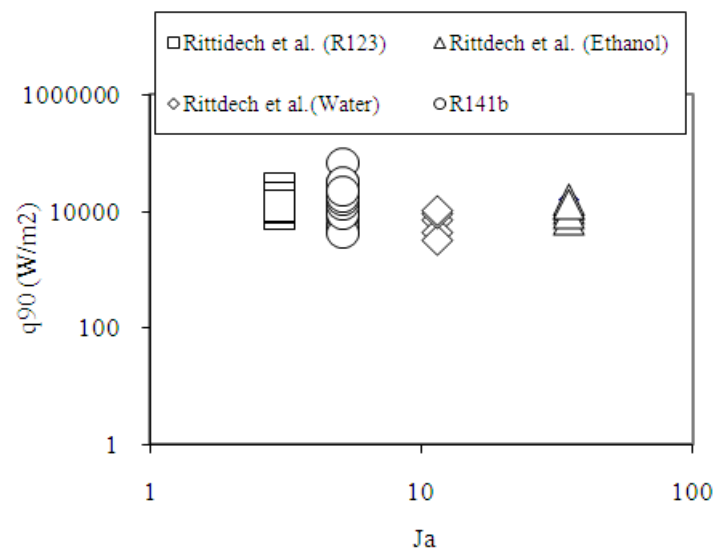

Fig. 7: Relationship of the Jacob number and heat flux of CEOHP

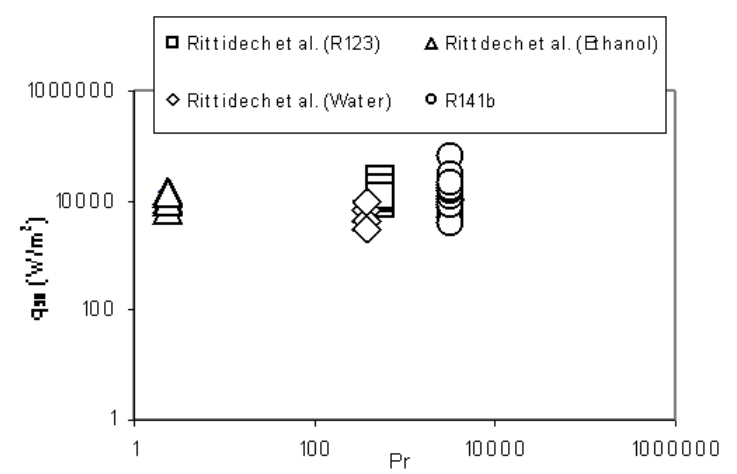

Fig. 8: Relationship of the Prandlt number and heat flux of CEOHP

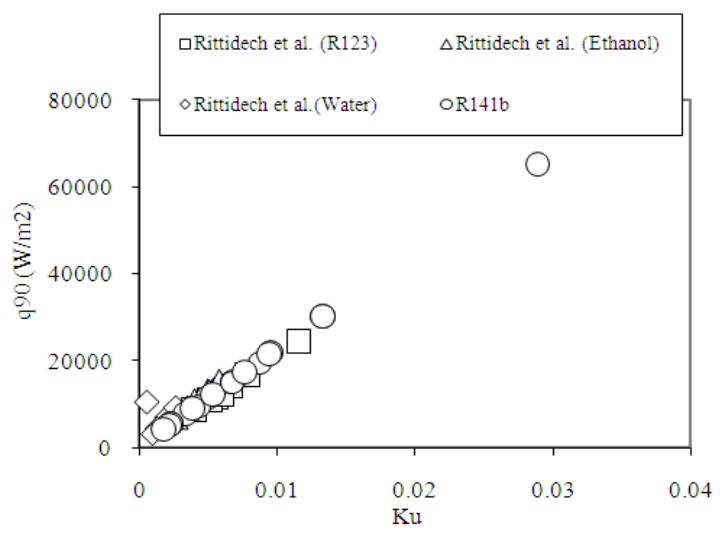

Fig. 9: Relationship of the Kutateladze number and heat flux of CEOHP 


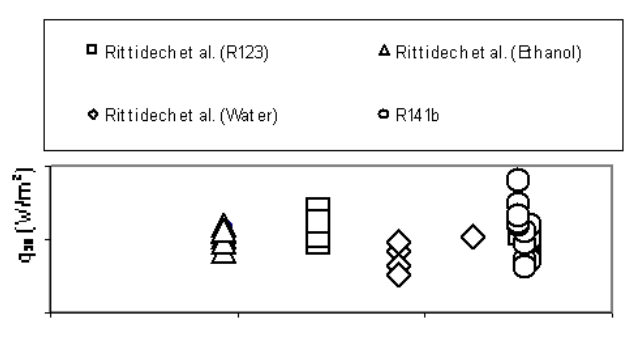

$\left(\omega \mu v^{3} / \sigma^{2} \rho\right)$

Fig. 10: Relationship of the Self-excited oscillation and heat flux of CEOHP

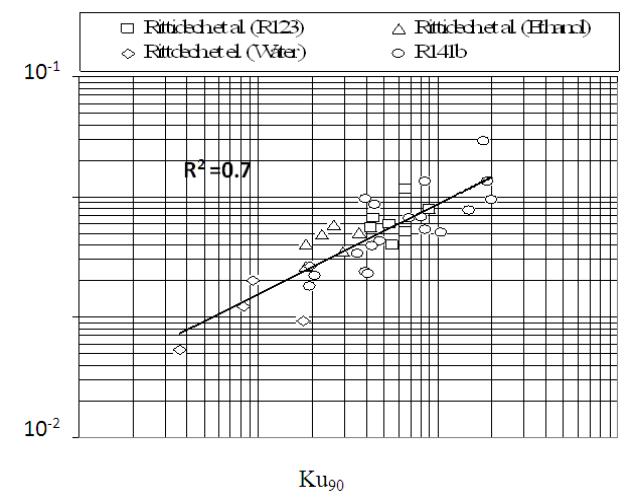

Fig. 11: Relationship of the Kutateladze number and dimensions of CEOHP

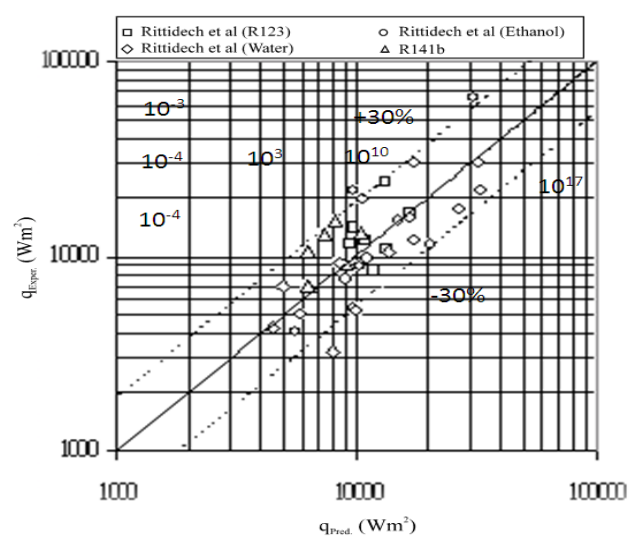

Fig. 12: The relationship between prediction and experiments of a CEOHP

From the discussion of all concerned dimensionless parameters, it can be concluded that the important dimensionless parameters which have an effect on heat flux of a CEOHP at vertical position are n, Bo, Le/d, We, Pr, Ja, Ku, $\left(\omega \mu v^{3} / \sigma^{2} \rho_{v}\right)$. These parameters were used to establish a correlation to predict the heat transfer characteristics of CEOHP.

Correlation of heat flux at vertical position: The correlation of dimensionless parameters can be evaluated from the discussion of the effect of the important dimensionless parameters, n, Bo, $\mathrm{L}_{\mathrm{e}} / \mathrm{D}, \mathrm{We}$, $\mathrm{Ja}, \operatorname{Pr}$ and $\left(\omega \mu v^{3} / \sigma^{2} \rho_{v}\right)$ on the heat flux of a CEOHP at vertical position as shown in Fig. 12. This figure shows the relationship $(\mathrm{Bo})^{2}\left(\mathrm{~L}_{\mathrm{e}} / \mathrm{D}\right)^{-0.67}(\mathrm{n})^{0.93}(\mathrm{We})^{2.09}(\mathrm{Ja})^{-1.37}$ $(\operatorname{Pr})^{-0.19}\left(\omega \mu v^{3} / \sigma^{2} \rho_{v}\right)^{0.01}$ of and Ku of the tested CEOHP in this research and the data ${ }^{[2]}$ at vertical position. The correlation had a coefficient of determination on $\mathrm{R}^{2}$ in this equation of 0.7 . In the interval of $8.69 \times 10^{-1}<(\mathrm{Bo})$ ${ }^{2}\left(\mathrm{~L}_{\mathrm{e}} / \mathrm{D}\right)^{-0.67}(\mathrm{n}){ }^{0.93}(\mathrm{We})^{2.09}(\mathrm{Ja})^{-1.37}(\mathrm{Pr})^{-0.19}\left(\omega \mu v^{3} / \sigma^{2} \rho_{v}\right)$ ${ }^{0.01}<5.73 \times 10^{11}$, Ku varies from 0.00053 to 0.02885 . It was found from the dimensionless analysis $\mathrm{Ku}$ is power function of $(\mathrm{Bo})^{2}\left(\mathrm{~L}_{\mathrm{e}} / \mathrm{D}\right)^{-0.67}(\mathrm{n})^{0.93}(\mathrm{We})^{2.09}(\mathrm{Ja})^{-1.37}(\mathrm{Pr})^{-}$ ${ }^{0.19}\left(\omega \mu v^{3} / \sigma^{2} \rho_{v}\right)^{0.01}$ as shown in Eq. (4):

$$
\mathrm{Ku}_{90}=0.0007\left[\begin{array}{l}
(\mathrm{Bo})^{2}\left(\frac{\mathrm{L}_{\mathrm{e}}}{\mathrm{D}}\right)^{-0.67}(\mathrm{n})^{0.93} \\
(\mathrm{We})^{2.09}(\mathrm{Ja})^{-1.37}(\mathrm{Pr})^{-0.19}\left(\frac{\omega \mu_{v}^{3}}{\sigma^{2} \rho_{v}}\right)^{0.01}
\end{array}\right]^{0.11}
$$

From this equation, the meaning of each parameter can be discussed as follows.

$\mathrm{Ku}_{90}$ indicates the ratio of heat flux of critical heat flux for the vertical position.

Bo indicates the boiling phenomenon at the evaporator section of a CEOHP as shown in Fig. 6. The Bo higher than one, it could be boiling phenomenon and low heat flux occurs. However if Bo is one, it shows that the ratio of buoyancy force to surface tension force working fluid, it will be equal. Could not boiling phenomenon and heat flux cannot occur.

$\mathrm{L}_{\mathrm{e}} / \mathrm{d}$ indicates the geometric size of a CEOHP. When the Le/d increases. The geometric size of a CEOHP is high size and thin, the boiling phenomenon approaches boiling inside a confined channel which low heat flux occurs. When the Le/d decreases . The geometric size of a CEOHP had short size and fat, the boiling phenomenon approaches pool boiling and at pool boiling high flux occurs.

$\mathrm{N}$ indicates the number of capillary tubes which are connecting the evaporator and the condenser section of a CEOHP, it represents the number of turns of a CEOHP. If the number of turns increases the heat flux will increases.

We have indicated the counter flow phenomena between the vapor bubble moves from the evaporator into the condenser section of liquid film occur condense in the condenser section returns flow in the evaporator section. If we increased, the heat flux increased .It shows as the liquid film is cannot flow with vapor bubble. Therefore, liquid film on the wall tube it can be returns flow to the evaporator section.

$\mathrm{Ja}$ indicates the liquid film moves down from the condenser to evaporator section at the wall tube. It was occurred latent and buoyancy moves up to the condenser section with vapor bubble. Liquid films will depress slightly than the heat flux decreased. Because the volume of liquid film flow returns to heat source, it will decrease. 
Pr indicates the ratio of momentum diffusivity to thermal diffusivity of the vapor slug if the value of Pr is very high, the heat transfer of vapor will be much:

$\left[(\mathrm{Bo})^{2}\left(\frac{\mathrm{L}_{\mathrm{e}}}{\mathrm{D}}\right)^{-0.67}(\mathrm{n})^{0.93}(\mathrm{We})^{2.09}(\mathrm{Ja})^{-1.37}(\mathrm{Pr})^{-0.19}\left(\frac{\omega \mu_{\mathrm{v}}^{3}}{\sigma^{2} \rho_{\mathrm{v}}}\right)^{0.01}\right]$

Higher than the momentum transfer i.e. the vapor slug will be able to transfer the thermal energy to the condenser section efficiently. Therefore, the value of $\mathrm{Ku}$ or heat flux will be high.

$\left(\omega \mu_{v}^{3} / \sigma^{2} \rho_{v}\right)$ indicates the oscillation phenomena of the working fluid in the CEOHP. The phenomena will be occurs when the heat pipe obtains heat at the evaporator section.

The heat flux of a CEOHP at vertical position can be easily evaluated from the Eq. (4) and compared to the heat flux from the experiment as shown in Fig. 12.This figure shows the comparison of heat flux from the experiment to heat flux from the prediction of Eq. (4) the tested CEOHP in this research and those of Rittidech et $\mathrm{al}^{[2]}$. Good agreements were achieved. All data in this figure are similar to the results in Fig. 12. A solid line which is inclined at 45 degrees from the horizontal axis represents the equation line that occurs when the heat flux from the prediction of Eq. (4) It can be seen that the standard deviation (STD) of heat flux in the experiment from the prediction of Eq. (4) is \pm $30 \%$. Thus Eq. (4) can be used to predict the heat flux of a CEOHP at vertical position.

It can be seen that the correlation of heat flux of a $\mathrm{CEOHP}$ at vertical position or the correlation of $\mathrm{Ku}$ and $(\mathrm{Bo})^{2} \quad\left(\mathrm{~L}_{\mathrm{e}} / \mathrm{D}\right)^{-0.67}(\mathrm{n})^{0.93}(\mathrm{We})^{2.09}(\mathrm{Ja})^{-1.37}(\mathrm{Pr})^{-0.19}$ $\left(\omega \mu v^{3} / \sigma^{2} \rho_{v}\right)^{0.01}$ is the Eq. (4) and the coefficient of determination $\left(\mathrm{R}^{2}\right)$ of this equation is 0.7 . It can be seen that the data closely follow the solid line representing Eq. (4).

\section{CONCLUSION}

From all of the results obtained, it can be concluded that:

* As the number of turns increased, the heat flux increased.

* As the inner diameter increased, the heat flux increased.

* As the aspect ratio increased, the heat flux decreased:

$\mathrm{Ku}_{90}=0.0007\left[\begin{array}{l}(\mathrm{Bo})^{2}\left(\frac{\mathrm{L}_{\mathrm{e}}}{\mathrm{D}}\right)^{-0.67}(\mathrm{n})^{0.93} \\ (\mathrm{We})^{2.09}(\mathrm{Ja})^{-1.37}(\mathrm{Pr})^{-0.19}\left(\frac{\omega \mu_{\mathrm{v}}^{3}}{\sigma^{2} \rho_{\mathrm{v}}}\right)^{0.01}\end{array}\right]^{0.11}$

Was derived as a correlation to predict heat flux in vertical position.

\section{ACKNOWLEDGMENT}

The research has been supported generously by the Faculty of Engineering Mahasarakham University. The authors express their sincere appreciation for all of the support provided.

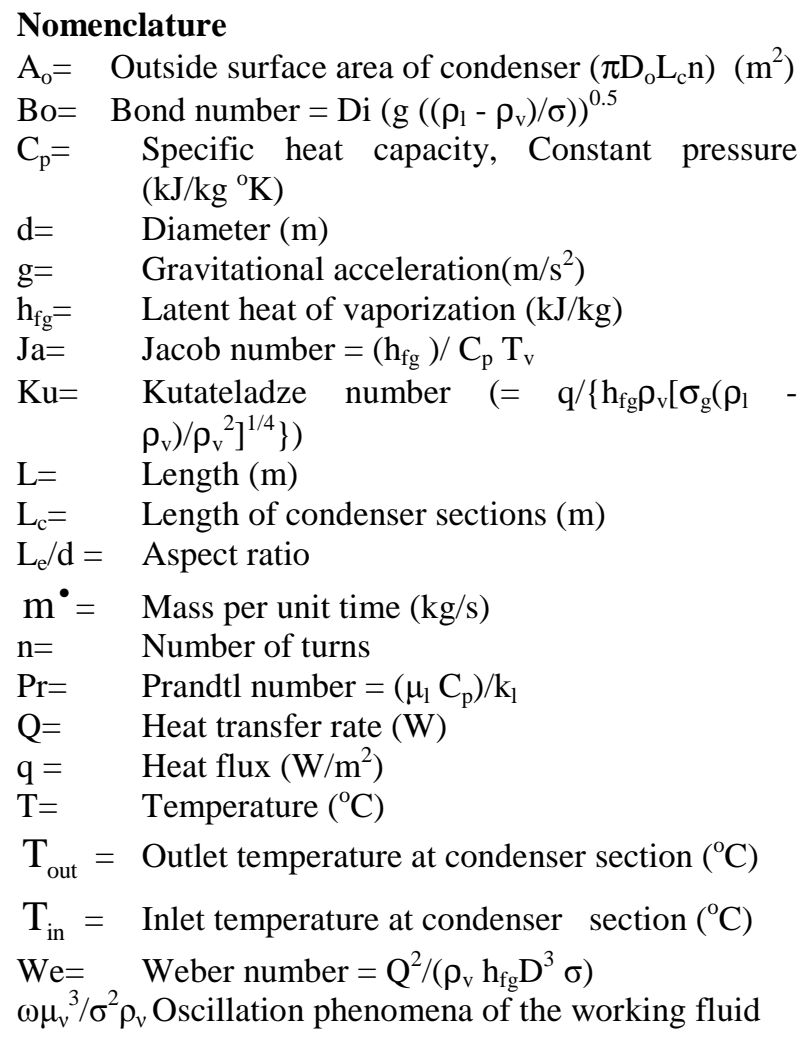

\section{Greek symbols}

$\mathrm{k}=\quad$ Thermal conductivity (W/m.K)

$\mu=\quad$ Viscosity (Pa.s)

$\rho=\quad$ Density $\left(\mathrm{kg} / \mathrm{m}^{3}\right)$

$\sigma=\quad$ Surface tension $(\mathrm{N} / \mathrm{m})$

\section{Subscripts \\ e $\quad=$ Evaporator \\ $1 \quad=$ Liquid \\ $\mathrm{V} \quad=$ Vapor \\ $\mathrm{i} \quad=$ Inside \\ o $\quad=$ Outside \\ $90=$ =Inclination angles (degree)}

\section{REFERENCES}

1. Maesawa, S., K. Gi, A. Minamisawa and H. Akachi, 1996. Thermal performance of capillary tube thermosyphon. IX Intl. Heat Pipe Conf. Albuquerque, New Mexico, 2: 791-795.

2. Rittidech, S., P. Terdtoon, M. Murakami, P. Kamonpet and W. Jompakdee, 2003. Correlation to predict heat transfer characteristics of closed-end oscillating heat-pipe (CEOHP) at normal operating conditions. Procs. the Appl. Thermal Engg., pp: 497-510.

3. Waowaew, W., P. Terdtoon, P. Kamonpet and W. Klongpanich, 2003. Correlation to predict heat transfer characteristics of a radially rotating heat pipe at vertical position. Procs. Appl. Thermal Engg., 23: 19-1032. 